\title{
ENVIRONMENTALLY FRIENDLY MONOLITHIC HIGHLY-POROUS BIOCARBONS AS BINDER-FREE SUPERCAPACITOR ELECTRODES
}

\author{
Tatiana S. Orlova ${ }^{1,2}$, Vitaly V. Shpeizman ${ }^{1}$, Nadejda V. Glebova1, \\ Andrey A. Nechitailov ${ }^{1}$, Andrey A. Spitsyn ${ }^{3}$, Dmitry A. Ponomarev ${ }^{3}$, \\ Antonio Gutierrez-Pardo ${ }^{4}$ and Joaquin Ramirez-Rico ${ }^{4}$
}

${ }^{1}$ Ioffe Institute, Russian Academy of Sciences, ul. Politekhnicheskaya 26, St. Petersburg, 194021 Russia ${ }^{2}$ National Research University of Information Technologies, Mechanics and Optics, pr. Kronverkskii 49, St. Petersburg, 197101 Russia

${ }^{3}$ St. Petersburg State Forest Technical University, per. Institutskiy 5, St. Petersburg, 194021 Russia

${ }^{4}$ Dpto. Física de la Materia Condensada. Instituto de Ciencia de Materiales de Sevilla (ICMS),

Universidad de Sevilla, Consejo Superior de Investigaciones Científicas (CSIC), Avda. Reina Mercedes S/N, 41012 Sevilla, Spain

Received: November 11, 2017

\begin{abstract}
A simple, low-cost and environmentally friendly method has been used to obtain highly porous biomorphic carbon monoliths with a good combination of interconnected macro-, mesoand microporosity, and good electrical conductivity and mechanical strength, making these biocarbon materials interesting for electrochemical applications as binder-free electrodes. Highly porous monolithic biocarbons were obtained from beech wood precursors through pyrolysis and subsequent surface modification in a steam heated to $970^{\circ} \mathrm{C}$ with different activation times. The obtained biocarbons demonstrated good electrical conductivity and mechanical strength. They were studied as electrodes for supercapacitors in half cell experiments, demonstrating maximum gravimetric capacitance of $200 \mathrm{~F} \mathrm{~g}^{-1}$ in a basic media at scan rate $1 \mathrm{mV} \mathrm{s}^{-1}$. Galvanostatic charge-discharge experiments showed maximum capacitance of $185 \mathrm{~F} \mathrm{~g}^{-1}$ at current density of $0.15 \mathrm{~A} \mathrm{~g}^{-1}$ and $\sim 100 \mathrm{~F} \mathrm{~g}^{-1}$ at current density of $0.75 \mathrm{~A} \mathrm{~g}^{-1}$. It has been shown that in addition to the developed porous surface, the micropores with diameters exceeding $1 \mathrm{~nm}$ play a key role for the enhanced electrochemical capacity. Long-cycling experiments demonstrated excellent stability of the monolithic biocarbon electrodes with no reduction of the initial capacitance values after 600 cycles in voltammetry.
\end{abstract}

\section{INTRODUCTION}

Nowadays much attention is devoted to developing renewable energy storage devices with good storage capacity, which are environmentally friendly and at the same time have a low cost. Supercapacitors are considered as very important devices in the generation-storage-consumption chain of renewable energies, along with batteries and fuel-cells [1]. This is because, although having lower energy density than batteries, supercapacitors can deliver high power densities.
The capacitance of a supercapacitor is largely dependent on the characteristics of the electrode material. Among the materials that can be used as electrode in supercapacitors (conducting polymers [2], transition-metal oxides [2,3]) carbon materials have attracted special attention due to their good electrical conductivity, high surface area, interconnected pore structure, pore size matching to electrolyte ion size, excellent chemical stability, low cost and availability [4]. Carbon materials are very attractive for use as electrodes since they can be

Corresponding author:T.S. Orlova, e-mail: orlova.t@mail.ioffe.ru

(C) 2018 Advanced Study Center Co. Ltd. 
processed to have high specific surface areas, which is a requirement for high energy density in the double charged layer storage mechanism.

In addition to good functional properties, important requirements for electrodes, including carbon ones, are low cost and environmental friendliness of the method of their preparation, sufficient initial strength, reliability in operation and high charge-discharge cycling stability. Activated carbons are commonly employed due to their low cost [4]. Most activated carbons are usually obtained in the form of fine powders by chemical activation $[5,6]$. Recently, biomass materials have become popular to use as a precursor for carbon electrode for supercapacitor application such as rubber wood sawdust [5], peanut [7] and rise shells [8], and poplar wood [9]. The manufacture of electrodes from powder requires the addition of a binder (usually polymers [10]) in large amount varying from 5 to 10 $w t . \%$. The binder can block part of the porosity [11] and also lead to a decrease of the electrical conductivity [12]. This is undoubtedly a shortcoming of binder-containing electrodes. Thus, the possibility of using activated carbon materials without any binders gives an additional benefit for the construction of electrode. Therefore, developing monolithic carbon structures for electrodes to supercapacitors is a challenge task. Some monolithic structures (aerogels [13,14], templates from silica monoliths [15], microporous activated carbon monoliths synthesized from mesophase pitch [11]) have been produced for electrochemical applications. However the reported capacitance values for such structures are mostly modest, and their synthesis is quite expensive and not environmentally friendly, so alternatives are desirable.

In this paper we obtained the activated woodderived carbon monoliths and demonstrated their application as binder-free electrodes for supercapacitor. The wood precursor (beech wood) was carbonized in an inert atmosphere and subsequently activated at high temperature in a stream of water vapour with different activation times. As a result, porous monolithic biocarbon scaffolds with interconnected hierarchical porosity and large pore volumes were obtained. The microstructure, strength, electrical conductivity and electrochemical behavior of the biocarbon scaffolds are analyzed in comparison with the non-activated wood-derived monolithic carbon. The obtained activated monolithic biocarbons have electrochemical characteristics comparable to those of electrodes built of the best performing activated carbon powders for industrial supercapacitors, but they have advantage, because they can be used as electrodes without any binding or conductive additives.

\section{EXPERIMENTAL}

Wood-derived carbons were produced by carbonization of beech (Fagus sylvatica) precursors in an inert atmosphere. The technique for preparing biocarbons was described in detail, for example, in [16].

Samples of $(9 \times 9 \times 9) \mathrm{mm}^{3}$ in size were cut and activated with steam at $970^{\circ} \mathrm{C}$, the duration of activation being varied from 1 to $15 \mathrm{~min}$. For the activation, the biocarbon samples were placed in a rotating tubular reactor with a mesh barrier; the rotation speed was $1 / 60 \mathrm{~Hz}$. The reactor with samples was placed in a tube furnace and purged with steam. The duration of heating to $970^{\circ} \mathrm{C}$ was $3 \mathrm{~min}$. After heating the reactor to a predetermined temperature, the activation time was counted. After completing a given activation time, the supply of steam was stopped, and the reactor was cooled in air. The relative change in the weight $(\Delta w)$ of the sample was selected as the characteristic parameter of activation effectiveness. The rate of weight loss in the sample upon the activation was high at the beginning of the process: after the activation time of $t=1$ $\mathrm{min}$, the weight of the sample decreased by $\sim 18 \%$. Then the rate of weight change fell. A prolonged treatment with steam over 15 min resulted, in most cases, in the cracking of the sample.

In this work we conducted a study of samples with a change in their weight after activation of approximately $15,20,28$, and $31 \%$. For comparison the initial, non-activated samples were also investigated. Hereafter, the samples without activation are denoted as bioC_0, the samples with subsequent activation with weight loss $\Delta w$ are denoted as bioC_ $\Delta w$. bioC_15, bioC_20, bioC_28, and bioC_31.

Samples were studied to determine the effect of the steam activation at $970^{\circ} \mathrm{C}$ on the degree of crystallinity. Crystallinity was determined by X-ray diffraction in a powder diffractometer (Bruker D8 Advance).

The porous structure of the samples was studied by low-temperature nitrogen adsorption using a Micromeritics ASAP 2020 Analyzer. Samples previously were outgassed at $30^{\circ} \mathrm{C}$ during $1 \mathrm{~h}$, then at $250^{\circ} \mathrm{C}$ during $2 \mathrm{~h}$ and placed in a Dewar vessel to analyze the adsorbed and desorbed amount in $\mathrm{N}_{2}$ at $77 \mathrm{~K}$ in the relative pressure range of $P / P_{0}=0-1$. The specific surface area and distribution of pores 
on the size were obtained by calculating the adsorption-desorption isotherms using the software of the device.

Mechanical properties of the samples $((3 \times 3 \times$ 8) $\mathrm{mm}^{3}$ in size) were investigated with stepwise compression along the long side of the sample with the loading steps $\Delta \sigma \approx 1.4 \mathrm{MPa}$ and the duration of constant loading $\Delta t=300 \mathrm{~s}$. The rate and magnitude of deformation were measured using a laser interferometer with the quantization frequency $f=500$ $\mathrm{Hz}$. This non-traditional method using a laser interferometer permits one to measure deformation precisely [17]. Stepped curves of stress-strain $(\sigma-\varepsilon)$ were approximated by smooth curves; the breaking stress (strength $\left.\sigma_{f}\right)$, limiting inelastic $\left(\varepsilon_{\text {inelast }}\right)$ and total $\left(\varepsilon_{\text {total }}\right)$ strain at the time of the sample destruction were determined from these curves.

Bulk electrical resistivity was measured in a temperature range of 77-300K using a four-probe method [18]. Biocarbons were previously cut into bars with dimensions of about $(9 \times 3 \times 2) \mathrm{mm}^{3}$ and four copper wire contacts were attached on the $(3 \times 9) \mathrm{mm}^{2}$ side of a sample with silver paste. Biocarbon electrodes were prepared as nominal $(9 \times 9) \mathrm{mm}^{2}$ slabs with $\sim 1.5 \mathrm{~mm}$ thickness. The electrochemical measurements of the electrode materials were carried out using a galvanostat-potentiostat of the IPC Pro and Elins P20X types in a three electrode setup: wood-derived carbon samples were used as working electrodes, an $\mathrm{Ag} / \mathrm{AgCl}$ electrode was used as a reference (the measured potentials are given relative to this electrode) and platinum as the counter electrode. Aqueous solutions $1 \mathrm{M} \mathrm{KOH}$ and $1 \mathrm{M}$ $\mathrm{H}_{2} \mathrm{SO}_{4}$ were used as electrolytes (both solutions were in equilibrium with the air, but the background currents were insignificant compared to the measured ones). Cyclic voltammetry (CV) experiments were performed with scan rates $v$ ranging from 1 to $100 \mathrm{mV} \mathrm{s}^{-1}$, at potentials between -1.0 and $0.0 \mathrm{~V}$ in the case of $1 \mathrm{M} \mathrm{KOH}$ electrolyte and at potentials between -1.0 and $0.1 \mathrm{~V}$ in the case of $1 \mathrm{M} \mathrm{H}_{2} \mathrm{SO}_{4}$ electrolyte. The measured cyclic voltammograms were plotted as volt-farad curves in coordinates: differential capacitance $C_{\mathrm{CV}}$ - potential V, according to $C_{\mathrm{CV}}=l \mathrm{~d} t / \mathrm{d} V=I / v$, where $I$ is the current, scan rate $v=\mathrm{d} V / \mathrm{d} t$, $t$ is time.

Galvanostatic charge/discharge (GCD) experiments were performed at current densities ranging from 0.1 to $0.75 \mathrm{Ag}^{-1}$ at a potential window of $-1.0 \mathrm{~V}$ for $1 \mathrm{M} \mathrm{KOH}$ electrolyte and at a potential window of $0.9 \mathrm{~V}$ for $1 \mathrm{M} \mathrm{H}_{2} \mathrm{SO}_{4}$ electrolyte. Specific capacitance was calculated from the GCD curves according to the following equation:

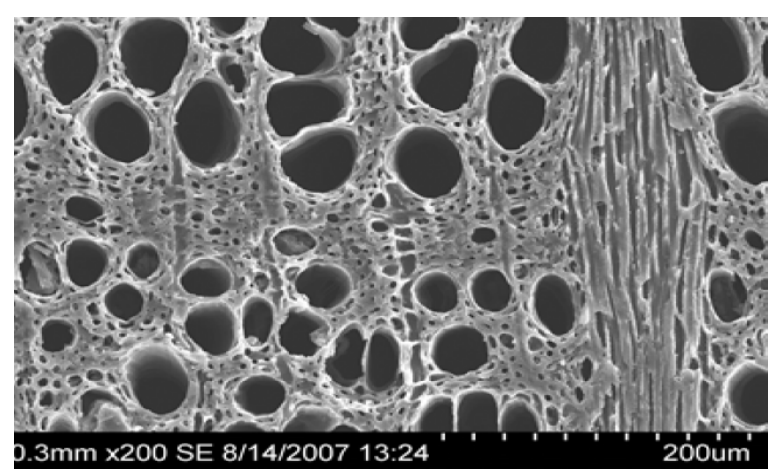

Fig. 1. Porous structure of non-activated biocarbon bioC_0.

$C_{G C D}=I \Delta t /(m \Delta V)$,

where $I$ is the charge/discharge current, $m$ is the mass of the biocarbon electrode, $\Delta t$ is the discharge time, and $\Delta V$ is the potential change during the discharge process.

The equivalent series resistance (ESR) was calculated from the galvanostatic cycles by dividing the voltage drop by the current intensity:

$$
\operatorname{ESR}(\Omega)=\text { Vdrop } / 2 \text { l. }
$$

The specific power $(P)$ was calculated from the GCD data using the following equation

$$
P=V I / m \text {, }
$$

where $V$ is voltage (excluding the $V_{\text {drop }}$ which occurs at the beginning of the discharge curve). The cyclic stability of the working electrode was tested for 600 cycles for activated biocarbons in cyclic voltammetry, at a scan rate of $10 \mathrm{mV} \mathrm{s}^{-1}$.

\section{RESULTS AND DISCUSSION}

\subsection{Structural characterization}

Biocarbons prepared by carbonization of wood (beech in our case) have predominantly channeltype pores elongated along the tree growth direction. Initial porous microstructure of beech-derived carbon (bioC_0) is shown in Fig. 1 (in a cross section perpendicular to the growth of the original tree). The macroporous structure is bimodal and consists of pores of small (3-7 $\mu \mathrm{m})$ and large $(22-38 \mu \mathrm{m}) \mathrm{di}-$ ameter, which are oriented along the tree growth direction. After the activation by steam the macroporous structure of biocarbon is kept providing good mechanical integrity.

Fig. 2 displays $X$-ray diffraction patterns of the bioC_0 and bioC_31 samples. The patterns of both samples contain diffuse halos characteristic of amor- 


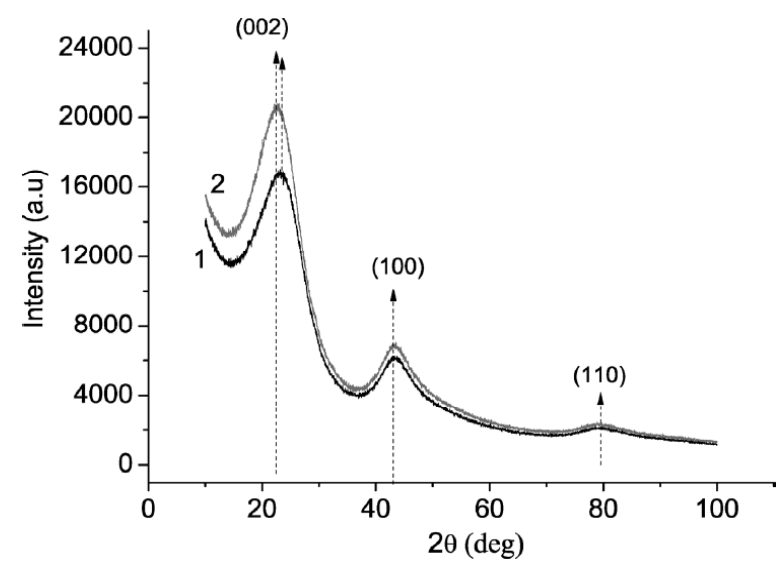

Fig. 2. X-ray diffraction patterns of non-activated biocarbon bioC_0 (1) and activated biocarbon bioC_31 (2).

phous (or amorphous to X-rays) material. Similar results were published in the literature for biocarbons derived from white eucalyptus, white pine, oak, poplar and beech [19-26]. For beech-derived biocarbon $\left(T_{\text {carb }}=1000^{\circ} \mathrm{C}\right)$, we have made detailed X-ray diffraction analysis in [26]. The analysis showed that in addition to the amorphous phase the biocarbons contain nanocrystallites of two types: graphite-type (graphite crystallization regions containing not less than two graphite layers) and graphen-type ones with the average size of $12 \AA$ and $26 \AA$, respectively [26]. As seen in Fig. 2, the high temperature activation with water vapor slightly increases the structure ordering: the volume of nanocrystalline phase somewhat increases, as evidenced in the increase of the (002) peak and the shift of the (002) spacings from the graphitic layers to a lower angle.

Activation by steam did not change the macroporous structure, but introduced meso- and microporosity. The specific surface area and porous structure of the biocarbon samples were investigated by $\mathrm{N}_{2}$ adsorption-desorption measurements. The typical adsorption-desorption isotherms and the pore size distribution curves of bioC_15 and bioC_31 are shown in Fig. 3. All activated samples exhibit a typeIV adsorption-desorption isotherm with hysteresis loops. On the basis of the adsorption-desorption isotherm, the Brunauer-Emmett-Teller (BET) surface area of the biocarbons was calculated. The pore size distribution was calculated from the adsorption-desorption isotherm by Density Functional Theory (DFT) method. Table 1 summarizes the pore characteristics of the activated biocarbons bioC_15, bioC_28 and bioC_31. The BET surface area and the total pore volume gradually rise up with the weight loss increase mainly due to fast growth of the contribution of mesoporosity. The ratio of mesoporosity
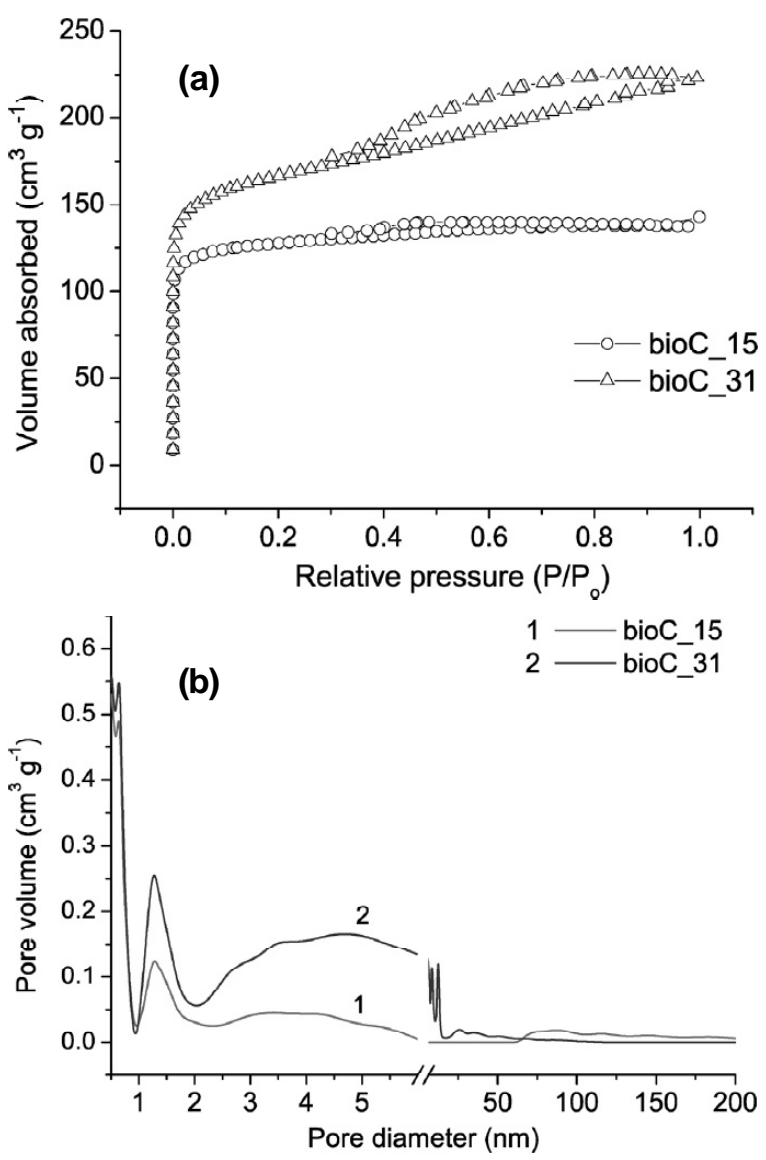

Fig. 3. (a) $\mathrm{N}_{2}$ adsorption/desorption isotherms and (b) pore size distribution curves for monolithic activated biocarbons bioC_15 and bioC_31.

to the total porosity increases from $8.7 \%$ for bioC_15 to $33.8 \%$ for bioC_28 and $43.8 \%$ for bioC_31; the average mesopore size increases from 3.2 to 4.3 and $5.9 \mathrm{~nm}$, respectively.

\subsection{Strength and plasticity}

The smoothed deformation curves (the stress $\sigma-$ strain $\varepsilon$ curves) under stepwise uniaxial compression for non-activated samples (curve 1) and activated samples with different weight losses (curve 2, Table 2) are presented in Fig. 4. Strength, total and inelastic strain before destruction of the initial and activated biocarbons are shown in Table 2. For the samples with smaller weight losses (curve 2, Table 2), there is a slight increase in the maximum stress compared with non-activated sample. As seen, all activated samples retain a reasonable mechanical integrity, the strength of the activated samples with weight loss up to $20 \%$ is even somewhat higher than the strength of the non-activated biocarbon. The increase of strength and strain before destruction after the activation (samples bioC_15 and bioC_20) is probably due to removing some surface 
Table 1. Specific surface area, pore volume and pore size of activated samples.

\begin{tabular}{lllllll}
\hline Sample & $\begin{array}{l}\text { BET specific } \\
\text { surface area, } \\
\left(\mathrm{m}^{2} \mathrm{~g}^{-1}\right)\end{array}$ & $\begin{array}{l}\text { DFT total } \\
\text { pore } \\
\text { volume, } \\
\left(\mathrm{cm}^{3} \mathrm{~g}^{-1}\right)\end{array}$ & $\begin{array}{l}\text { DFT } \\
\text { micropore } \\
\text { volume, } \\
\left(\mathrm{cm}^{3} \mathrm{~g}^{-1}\right)\end{array}$ & $\begin{array}{l}\text { DFT average } \\
\text { micropore } \\
\text { size }(\mathrm{nm})\end{array}$ & $\begin{array}{l}\text { DFT } \\
\text { mesopore } \\
\text { volume, } \\
\left(\mathrm{cm}^{3} \mathrm{~g}^{-1}\right)\end{array}$ & $\begin{array}{l}\text { DFT average } \\
\text { mesopore } \\
\text { size, }(\mathrm{nm})\end{array}$ \\
\hline bioC_15 & 446 & 0.184 & 0.160 & 0.58 & 0.016 & 3.2 \\
bioC_28 & 527 & 0.260 & 0.132 & 0.67 & 0.088 & 4.3 \\
bioC_31 & 581 & 0.290 & 0.163 & 1.2 & 0.127 & 5.9 \\
\hline
\end{tabular}

Table 2. Strength, complete and inelastic strain before destruction of the non-activated and activated biocarbons.

\begin{tabular}{llll}
\hline Sample & $\sigma_{\mathrm{f}}, \mathrm{MPa}$ & $\varepsilon_{\text {total }} \%$ & $\varepsilon_{\text {inelast }} \%$ \\
\hline bioC_0 & 27.5 & 0.75 & 0.44 \\
bioC_15 & 35.7 & 1.22 & 0.81 \\
bioC_20 & 31.1 & 0.82 & 0.47 \\
bioC_28 & 24.0 & 0.66 & 0.38 \\
bioC_31 & 14.2 & 0.37 & 0.22 \\
\hline
\end{tabular}

defects by the steam, as such defects could serve as stress concentrators under deformation. In the samples obtained at the highest activation time, the cracks form and grow at lower loads, leading to earlier crushing (samples bioC_31), this occurs most likely due to the nucleation of some surface defects during the activation at much longer times.

\subsection{Electrical resistivity}

Temperature dependences of electrical resistivity $\rho$ of the samples with different weight loss after the activation are shown in Fig. 5. The activation nei-

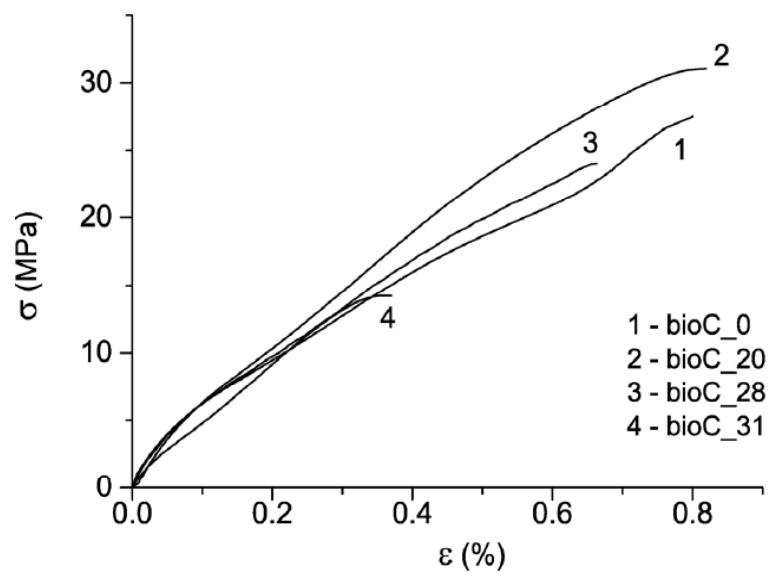

Fig. 4. Stress-strain curves obtained in compression for non-activated and activated biocarbon monoliths. ther changes the electrical resistivity much at room temperature (see insert to Fig. 5), nor the temperature dependence of $\rho$ with temperature. The value of $\rho$ at room temperature $\left(\rho_{\mathrm{RT}}\right)$ decreases with increasing $\Delta w$ up to $\Delta w \approx 20 \%$, then increases. Such behavior can be explained by two reasons. On the one hand, the conductivity can increase due to small increase in the degree of crystallinity, on the other hand, the weight loss leads to the introduction of mesoporosity thereby decreasing the conducting volume. The value of electrical resistivity of non-activated biocarbon bioC_0 at RT is about $1.510^{-2} \Omega \mathrm{m}$. The electrical resistivity of activated biocarbons at $\mathrm{RT}$ is in a range from 1.0 to $3.010^{-2} \Omega \mathrm{m}$, demonstrating good electrical conductivity comparable with the conductivity of the non-activated biocarbon.

\subsection{Electrochemical behavior}

The electrochemical study of biocarbons was carried out using cyclic voltammetry and galvanostatic charge-discharge cycling. Figs. 6a-6c show cyclic

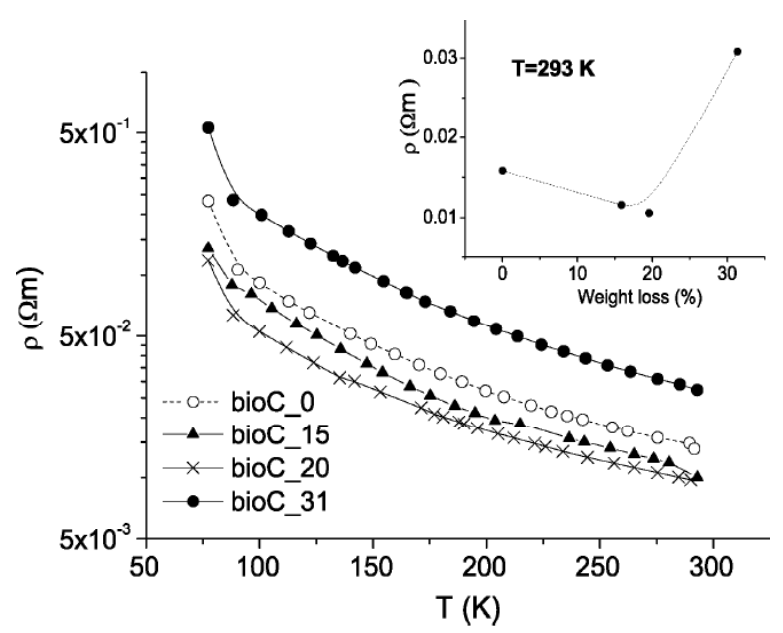

Fig. 5. Temperature dependence of the electrical resistivity of as processed and activated biocarbons with different weight losses. Insert: Electrical resistivity versus weight loss after activation. The resistivity was measured without regard for the porosity. 

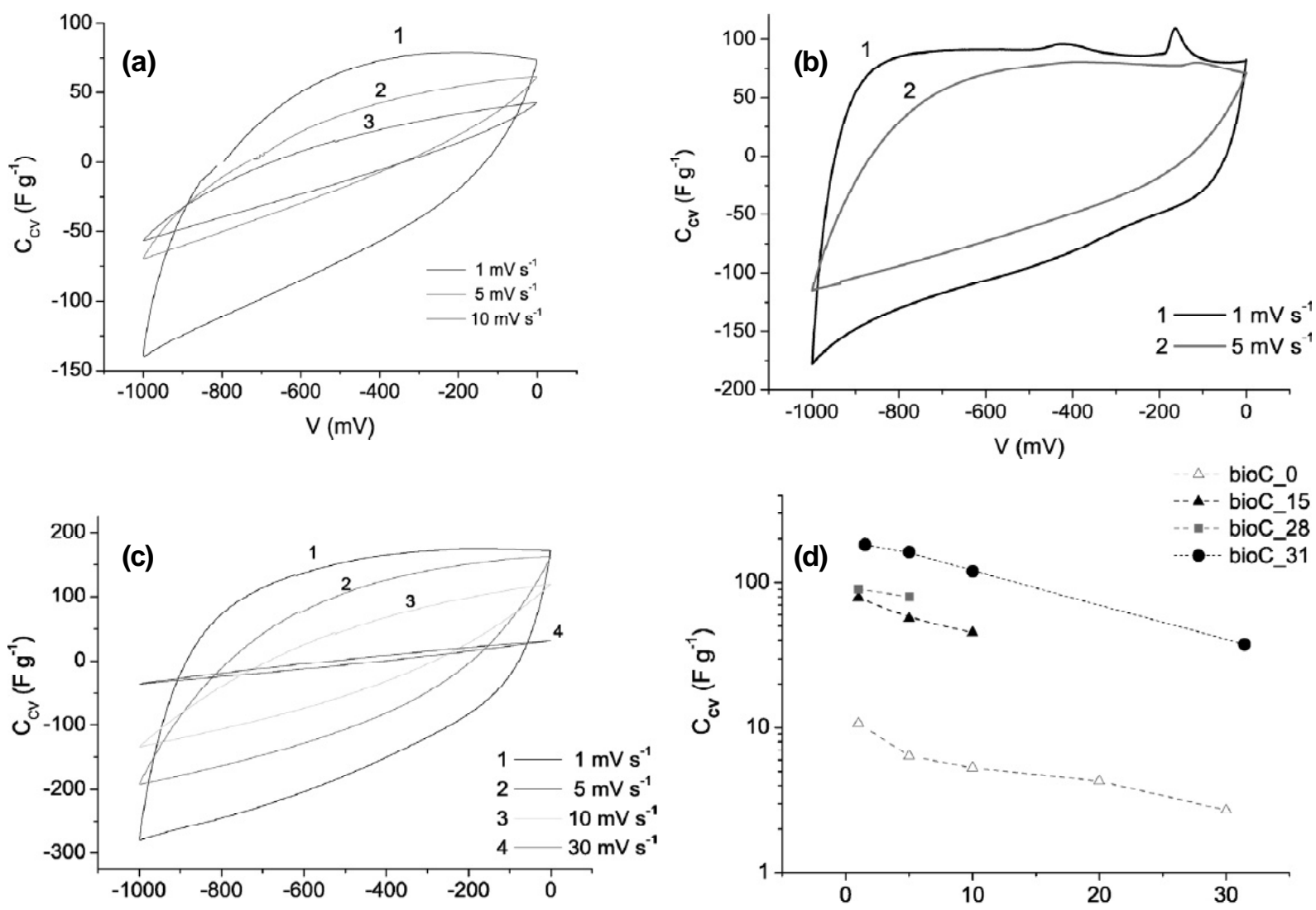

Fig. 6. Cyclic voltammetry curves of monolithic activated biocarbons with a weight loss of (a) $15 \%$, (b) $28 \%$ and (c) $31 \%$ at different scan rates; (d) dependence of maximum specific capacity on scan rate for monolithic biocarbons ( $1 \mathrm{M} \mathrm{KOH}$ electrolyte).

voltammetry curves (in coordinates: differential capacitance $C_{\mathrm{CV}}$ - potential $\mathrm{V}$ ) obtained in $1 \mathrm{M} \mathrm{KOH}$ electrolyte at different scan rates from $1 \mathrm{mV} \mathrm{s}^{-1}$ to $30 \mathrm{mV} \mathrm{s}^{-1}$ for biocarbons activated with different weight losses. The shape of the curves for bioC_15, bioC_28 and bioC_31 samples have evident rectangular parts, suggesting an EDLC (electric doublelayer capacitance) mechanism contribution. Further we will consider only the EDLC contribution. For comparison, $\mathrm{CV}$ measurements on the non-activated carbonized wood were also performed under identical conditions. Maximum volumetric EDLC capacitance at lowest scan rate $v=1 \mathrm{mV} \mathrm{s}^{-1}: C_{\mathrm{CV}}=185,90$, and $79 \mathrm{~F} \mathrm{~g}^{-1}$ for bioC_31, bioC_28, and bioC_15, respectively, whereas non-activated bioC_0 demonstrated low capacitance $C_{\mathrm{CV}}=10.7 \mathrm{~F} \mathrm{~g}^{-1}$ at the same scan rate. Fig. $6 \mathrm{~d}$ presents a variation of the $C_{\mathrm{CV}}$ of biocarbon electrodes versus the scan rate. There is no linear proportionality between the resulting capacitance $\mathrm{C}_{\mathrm{CV}}$ and the specific BET surface area (Table 1). This indicates that the specific BET surface area is not the only crucial factor for the formation of the electric double layer and for appropriate capacitive performance. The bioC_31 samples dem- onstrated nearly twice higher value of $\mathrm{C}_{\mathrm{CV}}$ compared with the bioC_28 samples though the specific BET surface areas and the volumes of total and mesoporosities for these two samples do not differ much. It seems that the high value of capacity was achieved in bioC_31 samples due to much higher contribution to electrochemical performance from micropores which have the average pore diameter $1.2 \mathrm{~nm}$ (Table 1) and, hence, provide better access to the electrolyte compared to the sample bioC_28, where the average micropore size is half.

For the monolithic activated biocarbon bioC_31, which demonstrated the highest value of $C_{\mathrm{CV}}$, the galvanostatic charge-discharge (GCD) behavior was also studied at various current densities from 0.1 to $0.75 \mathrm{Ag}^{-1}$. Fig. 7 a shows the typical GCD curves for the bioC_31 samples. The curves have a trianglelike shape that indicates their electric double-layer capacitive behavior. The results are in accordance with the $\mathrm{CV}$ curves. The specific capacitance $C_{\mathrm{GCD}}$ of the GCD curves was calculated according to the Eq. (1). Fig. $7 \mathrm{~b}$ demonstrates the change of $C_{\mathrm{GCD}}$ with increase of the current density. The value of $C_{\mathrm{GCD}}$ decreases rather slowly with the increase of 

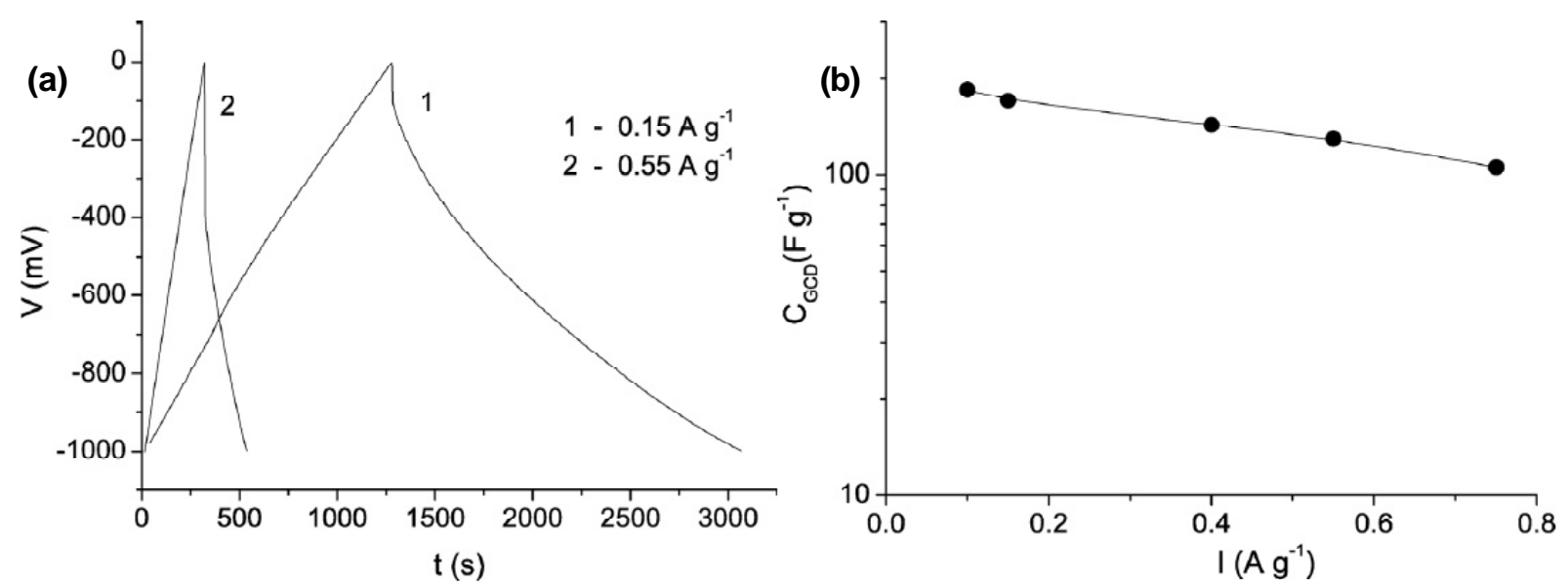

Fig. 7. Electrochemical testing results for monolithic activated biocarbon bioC_31: a) galvanostatic chargedischarge curves at various current densities; b) specific capacitance as a function of current density, based on the charge-discharge curves (1 $\mathrm{M} \mathrm{KOH}$ electrolyte).
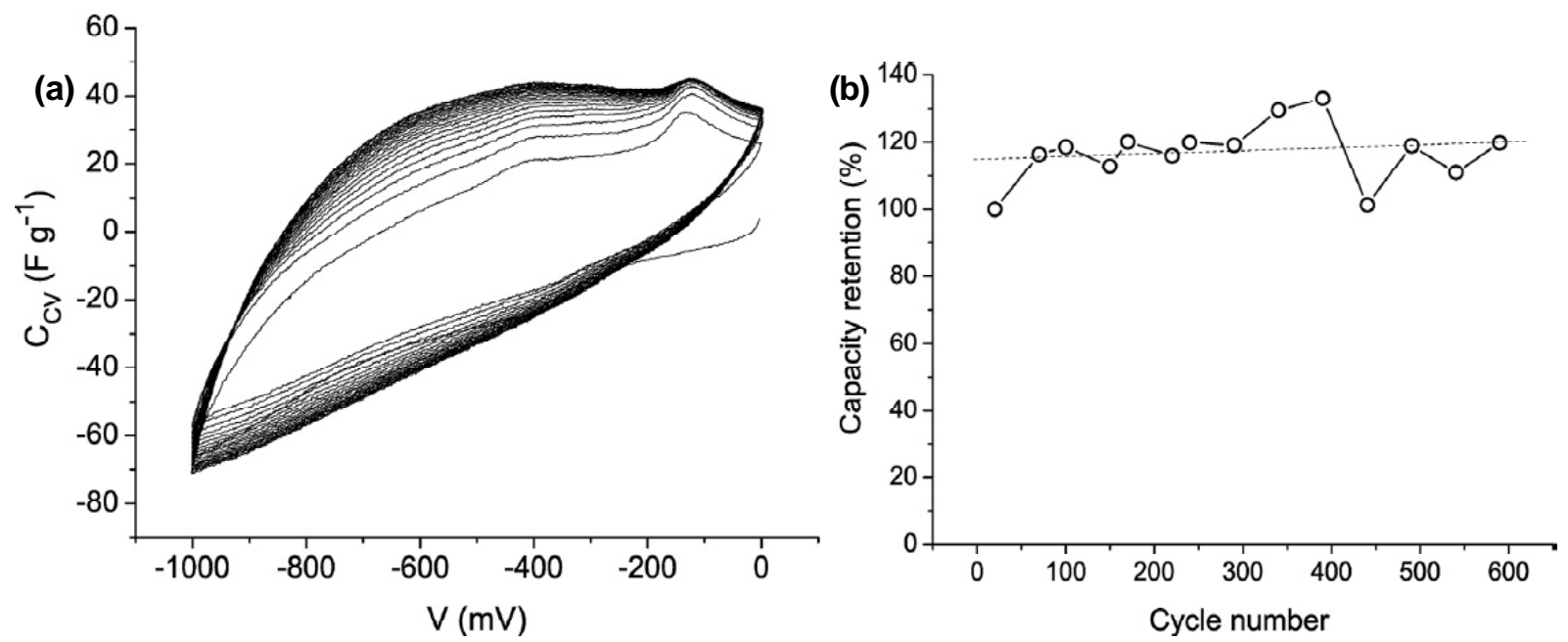

Fig. 8. Cyclic voltammetry curves for the first 20 cycles (a) and capacitance retention as a function of cycle number (b) for monolithic activated carbon bioC_15. The dashed line is only included as a guide to the eye. (1 M KOH electrolyte).

the current density, the maximum $C_{\mathrm{GCD}}=185 \mathrm{~F} \mathrm{~g}^{-1}$ was found at the current density $0.1 \mathrm{Ag}^{-1}$, whereas at $0.75 \mathrm{~A} \mathrm{~g}^{-1} C_{\mathrm{GCD}}=105 \mathrm{~F} \mathrm{~g}^{-1}$.

High cyclic stability is essential for operation of electrodes in supercapacitors. The long-term cycle stability of the biocarbon electrode was evaluated by repeating the $\mathrm{CV}$ voltammograms at the scan rate $10 \mathrm{mV} \mathrm{s}^{-1}$ for 600 cycles. The capacity retention as a function of cycle number is shown in Fig. 8. Excellent cyclic stability, even with some increase of capacity while cycling was observed.

We also performed some electrochemical measurements in $1 \mathrm{M} \mathrm{H}_{2} \mathrm{SO}_{4}$ electrolyte for the bioC_31, which demonstrated the highest capacity in $1 \mathrm{M}$ $\mathrm{KOH}$ electrolyte. The results are shown in Fig. 9, demonstrating $\mathrm{CV}$ curves at different scan rates (Fig. 9a), dependence of maximum specific capacity $C_{\mathrm{cv}}$ on scan rate (Fig. 9b), galvanostatic charge-discharge curves at various current densities (Fig. 9c) and specific capacitance $C_{\mathrm{GCD}}$ as a function of current density (Fig. 9d) for monolith bioC_31 in electrolyte $1 \mathrm{M} \mathrm{H}_{2} \mathrm{SO}_{4}$. The shape of the $\mathrm{CV}$ curves in this case is more symmetrical and close to rectangular suggesting an ideal EDLC mechanism (Fig. 9a). The maximum EDLC contribution to the capacity $C_{\mathrm{CV}}$ was found to be equal to $200 \mathrm{~F} \mathrm{~g}^{-1}$ at scan rate $1 \mathrm{mV} \mathrm{s}^{-1}, 185 \mathrm{~F} \mathrm{~g}^{-1}$ at scan rate $2 \mathrm{mV} \mathrm{s}^{-1}$, and $14 \mathrm{~F} \mathrm{~g} \mathrm{~g}^{-1}$ at scan rate $100 \mathrm{mV} \mathrm{s}^{-1}$ (Fig. 9b). Galvanostatic charge-discharge curves are shown in Fig. 9c. Maximum $C_{\mathrm{GCD}}=185 \mathrm{~F} \mathrm{~g}^{-1}$ was obtained at current density $0.15 \mathrm{Ag}^{-1}$, the capacitance slowly decreases with the increase of current density reaching $C_{\mathrm{GCD}} \approx 100 \mathrm{~F} \mathrm{~g}^{-1}$ at $0.75 \mathrm{Ag}^{-1}$ (Fig. 9d). The gradual decrease of capacitance with an increase of cur- 

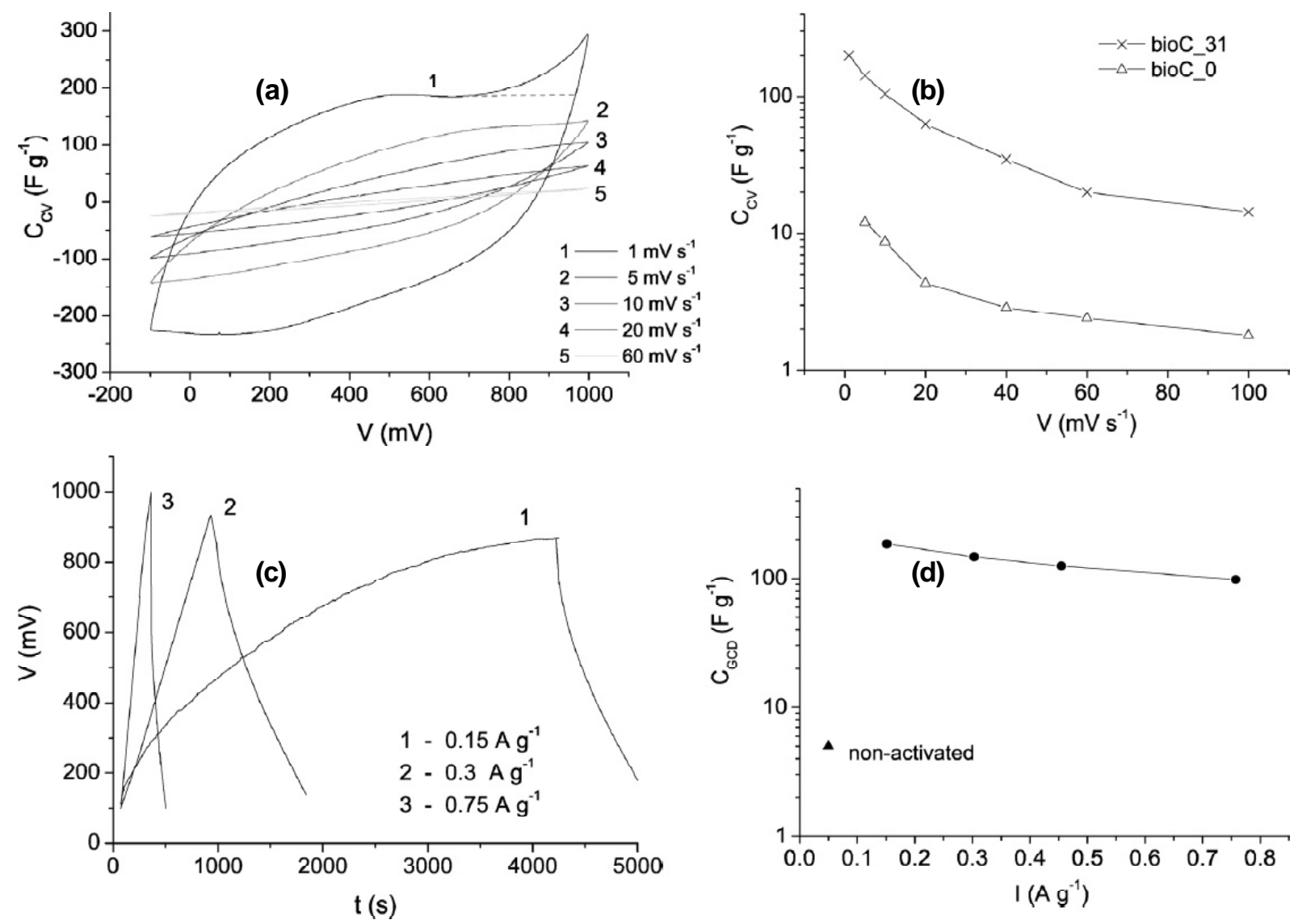

Fig. 9. Electrochemical testing results for monolith activated carbon bioC_31 in electrolyte $1 \mathrm{M} \mathrm{H}_{2} \mathrm{SO}_{4}$. a) Cyclic voltammetry curves at different scan rates, b) dependence of maximum specific capacity on scan rate, c) galvanostatic charge-discharge curves at various current densities, d) specific capacitance as a function of current density, based on the charge-discharge curves.

Current density $\left(\mathrm{A} \mathrm{g}^{-1}\right)$

rent density was mainly due to the incremental IR $\operatorname{drop}\left(V_{\text {drop }}\right)$, when the charging was replaced by discharging. The equivalent series resistance (ESR) was calculated with Eq. (2), the ESR was equal to $6 \Omega$. Fig. 10 shows the variation of specific capacitance $C_{\mathrm{GCD}}$ with power density for bioC_31. The obtained electrochemical behaviors of bioC_31 in 1 $\mathrm{M} \mathrm{H}_{2} \mathrm{SO}_{4}$ and $1 \mathrm{M} \mathrm{KOH}$ electrolytes are comparable, but the maximum capacitance $200 \mathrm{~F} \mathrm{~g}^{-1}$ was reached in $1 \mathrm{M} \mathrm{H}_{2} \mathrm{SO}_{4}$ for cyclic voltammetry at scan rate $1 \mathrm{mV} \mathrm{s}^{-1}$.

Table 3 shows the electrochemical performance of the monolithic bioC_31 electrode compared to an electrode built from the commercially àctivated carbon Maxsorb (90 wt.\% active mass + $10 \mathrm{wt} . \%$ binder (PVDF - polyvinylidene fluoride)) in $1 \mathrm{M} \mathrm{H}_{2} \mathrm{SO}_{4}$ [27]. The Maxsorb powder has a very high BET surface area (Maxsorb, Kansai, Japan; BET specific surface area: $3500 \mathrm{~m}^{2} \mathrm{~g}^{-1}$; micropore/mesopore volume ratio: 0.9 ) and it is considered as one of the best performing activated carbons for industrial supercapacitors [27]. Although the total porosity of

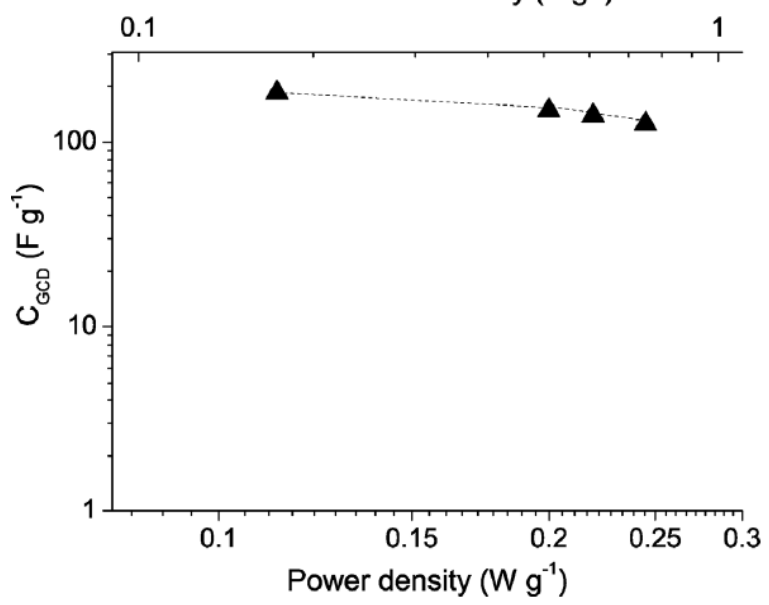

Fig. 10. Regone-type plot showing specific capacitances measured at different power densities, obtained from galvanostatic measurements for bioC_31. (1 $\mathrm{M} \mathrm{H}_{2} \mathrm{SO}_{4}$ electrolyte).

bioC_31 (BET surface area is equal to $580 \mathrm{~m}^{2} \mathrm{~g}^{-1}$ ) is much less than that of Maxsorb, the gravimetric capacitance values of both carbons are comparable. The specific capacitance per unit surface area 
Table 3. Comparison of characteristics of the monolithic bioC_31 electrode and the electrode built from the commercial activated carbon Maxsorb (90 wt.\% active mass + 10 wt. \% PVDF) in $1 \mathrm{M} \mathrm{H}_{2} \mathrm{SO}_{4}$. The capacitance values are compared for $\mathrm{CV}$ experiments using a $2 \mathrm{mV} \mathrm{s}^{-1}$ scan rate.

\begin{tabular}{llll}
\hline Sample & $C\left(\mathrm{~F} \mathrm{~g}^{-1}\right)$ & $C^{*}\left(\mu \mathrm{F} \mathrm{cm}^{-2}\right)$ & Ref. \\
\hline bioC_31 & 185 & 32 & This work \\
Maxsorb & 190 & 6 & {$[27]$} \\
\hline
\end{tabular}

$C^{\star}$ - specific capacitance per surface unit.

$\left(C^{\star}\right)$ of bioC_31 electrode is $32 \mu \mathrm{F} \mathrm{cm}{ }^{-2}\left(580 \mathrm{~m}^{2} \mathrm{~g}^{-1}\right)$, which is five times higher than that of the commercial carbon Maxsorb $\left(6 \mu \mathrm{F} \mathrm{cm}^{-2}\right)$ [27]. The capacitance values are compared for $\mathrm{CV}$ experiments in $1 \mathrm{M} \mathrm{H}_{2} \mathrm{SO}_{4}$ using a $2 \mathrm{mV} \mathrm{s}^{-1}$ scan rate (Table 3).

It is important to distinguish two principal types of binderless carbon monoliths. The first type is obtained by pressing carbon powder without any binder, with a subsequent sintering or heating step (see, for example, [28]). In doing so, the carbon powder before compacting or the obtained sintered monolith can be activated. In this case the connectivity of carbon particles is often non perfect and this affects the conductivity of the obtained carbon monoliths. The second type of the carbon monoliths is obtained by pyrolysis of polymers, wood or cellulosic precursors. Then such monolithic carbon is activated while maintaining its mechanical integrity. In these carbon monoliths the hierarchical macro-porosity of the wood precursor is retained and meso- and micropores are additionally induced.
The existing hierarchical macro-pores promote access of the electrolyte into the electrodes and can increase the charge transfer. The induced microand mesoporosity can strongly increase the specific surface area. Only few papers are devoted to the second types of monolithic carbons $[9,29,30]$. It should be noted that the wood-derived carbon monoliths reported in literature were chemically activated in a way that is costly and not environmentally friendly. We obtained the electrochemical characteristics for beech-derived monolithic carbon activated with water vapor and these characteristics are comparable with those for carbon monoliths which were chemically activated (Table 4). Such activation is ecologically clean and not a costly process, while maintaining mechanical integrity with good strength and electrical conductivity.

Thus, we have obtained highly porous wood-derived monolithic biocarbons which were produced at low cost in environmentally friendly conditions compared to chemically activated monolithic carbons. In practical application they can be used as electrodes without binders or conductive additives, or even current collectors, which are usually needed in the case of commercial activated carbons substantially decreasing thereby their performance per unit mass if we consider the total electrode mass and not only the 'active material' mass. Moreover the additives can partly block the porosity. These monolithic biocarbons have a well-developed interconnected network of macro-, meso-, and microporosity, and therefore can also serve as good scaffolds for developing the hybrid structures by depositing, for example, nano-sized particles of transition metal oxide onto their surfaces.

Table 4. Comparison of the preparation methods, specific surface area, capacitance and power density for different monolith wood-derived carbons.

\begin{tabular}{|c|c|c|c|c|c|}
\hline Material & Treatment & $\begin{array}{l}\text { BET specific } \\
\text { surface area, } \\
\left(\mathrm{m}^{2} \mathrm{~g}^{-1}\right)\end{array}$ & $\begin{array}{l}\text { Power } \\
\text { density, } \\
\left(\mathrm{W} \mathrm{kg}^{-1}\right)\end{array}$ & $\begin{array}{l}\text { Capacity, } \\
\left(\mathrm{F} \mathrm{g}^{-1}\right)\end{array}$ & Ref. \\
\hline Graphitic biocarbon & $\begin{array}{l}\text { Fe-catalyst } \\
\text { graphitization }\end{array}$ & 370.2 & $\sim 15$ & 133 & {$[30]$} \\
\hline Poplar-derived carbon & Chemical activation & 416 & n.a. & 234 & [9] \\
\hline Beech-derived carbon & $\begin{array}{l}\text { Physical activation by } \\
\text { water steam }\end{array}$ & 580 & 210 & 200 & $\begin{array}{l}\text { This } \\
\text { work }\end{array}$ \\
\hline $\begin{array}{l}\text { Rubber wood- } \\
\text { derived carbon }\end{array}$ & $\begin{array}{l}\text { Physical (in } \mathrm{N}_{2} \text { and } \\
\mathrm{CO}_{2} \text { gas atmosphere) }+ \\
\text { chemical activations }\end{array}$ & 331.5 & 420 & 154 & [29] \\
\hline
\end{tabular}

n.a. - not available 


\section{CONCLUSIONS}

In summary, monolithic biocarbons carbonized from beech wood have been activated in a rotating tubular reactor with steam. Variation of the steam treatment duration (or weight loss) allowed us to obtain carbon materials with surface area up to $580 \mathrm{~m}^{2} \mathrm{~g}^{-1}$. It has been shown experimentally that the activated monolithic biocarbons possess good electrical conductivity and mechanical strength which are comparable to as-pyrolyzed, non-activated biocarbon. The electrochemical studies show the great capacitive behavior of activated biocarbons: a strong increase in specific capacitance compared to the nonactivated biocarbon and excellent cycling stability. A maximum specific capacitance of $200 \mathrm{~F} \mathrm{~g}^{-1}$ was obtained in cyclic voltammetry experiments in basic media $\left(1 \mathrm{M} \mathrm{H}_{2} \mathrm{SO}_{4}\right)$ at scan rate $1 \mathrm{mV} \mathrm{s}^{-1}$. Galvanostatic charge-discharge experiments showed maximum capacitance of $185 \mathrm{~F} \mathrm{~g}^{-1}$ at current density of $0.15 \mathrm{~A} \mathrm{~g}^{-1}$ and $\sim 100 \mathrm{~F} \mathrm{~g} \mathrm{~g}^{-1}$ at current density of $0.75 \mathrm{~A} \mathrm{~g}^{-1}$. In addition to the developed porous surface, the micropores with diameters exceeding $1 \mathrm{~nm}$ play a key role for the enhanced electrochemical capacity. The obtained characteristics of the activated biocarbons are comparable with those of the electrodes built of the best performing commercial carbons with binding additives. This permits one to consider these monolithic biocarbons as promising materials for binderless monolithic electrodes.

\section{ACKNOWLEDGMENTS}

TSO thanks the Ministry of Education and Science of the Russian Federation for its support (Project No 3.3194.2017/4.6). The authors acknowledge specially M.A. Yagovkina for the performance of Xray diffraction measurements, which were carried out using equipment of the Joint Use Center "Materials Science and Diagnostics in Advanced Technologies."

\section{REFERENCES}

[1] A. Burke, R. Kotz and M. Carlen // J. Power Sources 91 (2000) 37.

[2] H. Zhao, G. Han, Y. Chang, M. Li and Y. Li // Electrochimica Acta 91 (2013) 50.

[3] D. Choi, G.E. Blomgren and P.N. Kumta // Adv. Mater. 18 (2006) 1178.

[4] E. Frackowiak and F. Beguin // Carbon 39 (2001) 937.
[5] E. Taer, M. Deraman, I. A. Talib, A. A. Umar, M. Oyama and R. M. Yunus // Curr. Appl. Phys. 10 (2010) 1071.

[6] H. Marsh, D.S. Yan, T.M. O'Grady and A. Wennerberg // Carbon 22 (1984) 603.

[7] X. He, P. Ling, J. Qu, M. Yu, X. Zhang, C. Yu and M. Zheng // J. Power Sources 240 (2013) 109.

[8] M.V. Lebedeva, P.M. Yeletsky, A.B. Ayupov, A.N. Kuznetsov, V.A. Yakovlev and V.N. Parmon // Mater. Renew Sustain. Energy (2015) 4:20l; DOI: 10.1007/s40243-015-0061-x.

[9] M. C. Liu, B. Kong, P. Zhang, Y. C. Luo and L. Kong // Electrochimica Acta. 60 (2012) 443.

[10] V. V. Obreja // AIP Conference Proceedings 1597 (2014) 98.

[11] V. Ruiz, C. Blanco, M. Granda, R. Menéndez and R.J. Santamaría // Appl. Electrochem. 37 (2007) 717.

[12] J. Gamby, P.L. Taberna, P. Simon, J.F. Fauvarque and M. Chesneau // J. Power Sources 101 (2001) 109.

[13] R. Saliger, U. Fischer, C. Herta and J. Fricke // J. Non-Cryst. Solids 225 (1998) 81.

[14] N. Hebalkar, G. Arabale, S.R. Sainkar, S.D. Pradhan, I.S. Mulla, K. Vijayamohanan, P. Ayyub and S.K. Kulkarni // J. Mater. Sci. 40 (2005) 3777.

[15] L.Z. Fan, Y.S. Hu, J. Maier, P. Adelhelm, B. Smarsly and M. Antonietti // Adv. Funct. Mater. 17 (2007) 3083.

[16]. M. A. Bautista, A. R. de Arellano Lopez, J. Martnez-Fernandez, A. Bravo-Leon and J. M. Lopez-Cepero // Int. J. Refract. Met. Hard Mater. 27 (2009) 431.

[17] V. V. Shpeizman, T. S. Orlova, B. K. Kardashev, B. I. Smirnov, A. Gutierrez-Pardo and J. Ramirez-Rico // Phys. Solid State 56 (2014) 538.

[18] V.V. Popov, T.S. Orlova, E. Enrique Magarino, M.A. Bautista and J. Martinez-Fernandez // Phys. Solid State 53 (2011) 276.

[19] L. S. Parfen'eva, T. S. Orlova, N. F. Kartenko, N. V. Sharenkova, B. I. Smirnov, I. A. Smirnov, H. Misiorek, A. Jezowski, J. Mucha, A. R. de Arellano-Lopez, J. MartinezFernandez and F. M. Varela-Feria // Phys. Solid State 48 (2006) 441.

[20] L.S. Parfen'eva, T.S. Orlova, N F. Kartenko, N.V. Sharenkova, B.I. Smirnov, I.A. Smirnov, H. Misiorek, A. Jezowski, T.E. Wilkes and K.T. Faber // Phys. Solid State 50 (2008) 2245. 
[21] L.S. Parfen'eva, T.S. Orlova, N.F. Kartenko, N.V. Sharenkova, B.I. Smirnov, I.A. Smirnov, H. Misiorek, A. Jezowski, J. Mucha, A. R. de Arellano-Lopez and J. Martinez-Fernandez // Phys. Solid State 51 (2009) 2023.

[22] P. Greil, T. Lifka and A. Kaindl// J. Eur. Ceram. Soc. 18 (1998) 1961.

[23] C. E. Byrne and D. C. Nagle // Carbon 35 (1997) 267.

[24] A. K. Kercher and D. C. Nagle // Carbon 40 (2002) 1321.

[25] A. K. Kercher and D. C. Nagle // Carbon 41 (2003) 15.

[26] L.S. Parfen'eva, T.S. Orlova, N.F. Kartenko, N.V. Sharenkova, B.I. Smirnov, I.A. Smirnov, H. Misiorek, A. Jezowski, T.E. Wilkes and
K.T. Faber // Phys. Solid State 52 (2010) 1115.

[27] E. Raymundo-Pinero, F. Leroux and F. Beguin // Adv. Mater. 18 (2006) 1877.

[28] E. Taer, M. Daraman, I. A. Talib, A. Awitdrus, S. A. Hashmi and A. A. Umar // Int. J. Electrochem. Sci. 6 (2011) 3301.

[29] E. Taer, Yusriwandi, R. Taslim, I.D.M. Syam and M. Deraman // KnE Engineering 1 (2016) 1; DOI 10.18502/keg.v111.499: 10.18502/ keg.v1i1.499.

[30]A. Gutierrez-Pardo, J. Ramírez-Rico, R. Cabezas-Rodríguez and J. MartínezFernandez // J. Power Sources 278 (2015) 18. 